\title{
LA LIBERTAD EN LA OBRA DE NICOLÁS GÓMEZ DÁVILA
}

\author{
José Miguel Serrano Ruiz-Calderón \\ Profesor Titular de Filosofía del Derecho. UCM. \\ jmruizcalderon@der.ucm.es
}

\begin{abstract}
«Lo único que garantiza un buen gobierno es una estructura política y social que sólo permita gobernar poco» ${ }^{1}$.
\end{abstract}

\begin{abstract}
RESUMEN
El escritor colombiano Nicolás Gómez Dávila tiene la rara cualidad de haber despertado el entusiasmo de escritores disidentes como Savater o Volpi. Su peculiaridad de reaccionario literario le aleja del pensamiento conservador y en su crítica al mundo moderno entronca con la estirpe de Dostoievski, Nietzsche o Schopenhauer. Es muy relevante la reivindicación de la libertad individual concreta y su crítica al poder politico, donde se encuentran también ecos del pensamiento del escritor rumano Ciorán.

Palabras clave: libertad, aristocracia, crítica literaria, poder político, derecho consuetudinario, Nietzsche, Schopenhauer.
\end{abstract}

\section{ABSTRACT}

The Colombian writer Nicolás Gómez Dávila has the rare quality of having sparked the enthusiasm of dissident writers such as Savater or Volpi. His uniqueness as a literary reactionary distances him from conservative thinking and in bis criticism of the modern world he ties in with the Dostoevsky, Nietzsche and Schopenhauer school of thought. The claim for specific individual freedom and his criticism of political power, where there are also echoes of the reflections of the Romanian writer Ciorán, is very relevant.

Keywords: freedom, aristocracy, literary criticism, political power, Common Law, Nietzsche, Schopenhauer.

\section{ZUSAMMENFASSUNG}

Der kolumbianische Schriftsteller Nicolás Gómez Dávila besitzt die seltene Gabe, den Enthusiasmus der Dissidentenschriftsteller wie Savater oder Volpi entfacht zu

${ }^{1}$ Me permito iniciar el trabajo con este escolio de Nicolás Gómez Dávila, publicado originalmente en Sucesivos escolios a un texto implícito (vid. edición española Escolios a un texto implícito, Gerona, Atalanta, 2009, p. 1369). No me resisto a traer el dictum de Thomas Mann en una conferencia dictada en 1959: «Citar es también una forma de dar las gracias», aun cuando —eso sí- pretendo que nunca me sea aplicable el reproche de G. Ch. Lichtenberg: «No cesaba de buscar citas, todo lo que había pasado de un libro a otro sin detenerse en su cabeza». 
baben. Seine reaktionäre, literarische Eigentümlichkeit entfernt ibn vom konservativen Denken und bei seiner Kritik an der modernen Welt wird er zum Nachfahren von Dostojewski, Nietzsche oder Schopenhauer. Die Forderung nach konkreter individueller Freiheit und die Kritik der politischen Macht sind bei ibm sebr bedeutsam und bierin findet sich auch ein Widerhall des Denkens des rumänischen Schriftstellers Ciorán.

Schlüsselwörter: Freiheit, Aristokratie, Literaturkritik, politische Macht, Gewohnheitsrecht, Nietzsche, Schopenhauer.

SUMARIO: I. INTRODUCCIÓN.-II. IMPOTENCIA ANTE EL MUNDO.III. ANTIPATÍA ANTE EL CONSERVADURISMO.-IV. CRÍTICA DEL EXTREMISMO POLÍTICO.-V. LA SOLEDAD DEL REACCIONARIO AUTÉNTICO.-VI. ACTITUD CONTEMPLATIVA.-VII. LA PREOCUPACIÓN ESENCIAL TEOLÓGICA.-VIII. LA LIBERTAD EN GÓMEZ DÁVILA.

\section{INTRODUCCIÓN}

Nicolás Gómez Dávila, don Colacho Gómez para los escasos amigos que compartieron sus tertulias, es un autor de una obra que apenas empieza a conocerse, extraña al entorno en el que se desarrolló, alejada de los tópicos del pensamiento latinoamericano y esencialmente incómoda ${ }^{2}$. Cuando falleció en 1994 apenas había comenzado el proceso por el que ha conseguido el propósito determinante de nuestro pensador, la proyección de su obra más allá de sí mismo, de su entorno e incluso de aquellas personas a las que él llamaba compatriotas, que son los que comparten no el lugar de nacimiento, sino sus inquietudes, sus valores o buena parte de sus ideas. Y ello pese a que el autor bogotano, en su modestia, consideraba que el único propósito de todo el ocio en que discurría su vida parecía ser dejar un pequeño e íntimo libro: «No es una obra lo que quisiera dejar. Las

${ }^{2}$ Como describe Hernán Alejandro Olano García: «Lector incansable, compartía las tardes de los domingos con un selecto grupo de contertulios: su caballeroso adversario Gabriel García Márquez, quien expresó: "Si no fuera de izquierda, pensaría en todo y para todo como él”, y además Alberto Lleras Camargo, Mario Laserna Pinzón, Douglas Botero Boshell, Francisco Pizano de Brigard, Álvaro Mutis, Félix Wilches, Abelardo Forero Benavides, Hernando Téllez, Alberto Zalamea, Juan Gustavo Cobo Borda, Adolfo Castañón, y últimamente los extranjeros Martin Mosebach, o sus traductores al alemán Günther Rudolph Sigl y al italiano Franco Volpi y otros, que lo lanzaron al estrellato, ya que Gómez Dávila nemo profeta in patria» (H. A. Olano GARCíA, «Aproximación al pensamiento de Nicolás Gómez Dávila sobre los derechos fundamentales. Revisión de su obra de iure», Revista de Derecho, Universidad del Norte, 34, 239-282, 2010, p. 247). 
únicas que me interesan se hallan a una infinita distancia de mis manos. Pero un pequeño volumen que, de cuando en cuando, alguien abra. Una tenue sombra que seduzca a unos pocos. ¡Sí! Para que atraviese el tiempo, una voz inconfundible y pura» ${ }^{3}$. Nuestro pensador hizo bueno el dictum del mordaz satírico francés De La Bruyère en Les Caracteres (1688): «Los hombres están demasiado absortos en sí mismos para poder comprender o escuchar a los demás: eso explica que quien tiene un gran mérito y una modestia aún mayor pueda ser ignorado largo tiempo».

Su propósito, en buena parte cumplido, es incorporarse al comentario de la tradición en la que se integraba. Algo que parece importarle más que los honores, hacia los que mantenía una actitud displicente e ingeniosa: «Increíble que los honores enorgullezcan a quienes saben con quienes los comparten» ${ }^{4}$.

Como en toda su obra, aquí también se encuentran los ecos de sus antecesores, por ejemplo, en este caso del científico y «escritor fragmentario» alemán Lichtenberg que nos decía: «A lo largo de mi vida me han otorgado tantos honores inmerecidos que bien podría permitirme alguna crítica inmerecida» ${ }^{5}$ y que, a juicio de Kart Krauss, «cavaba más hondo que cualquiera, pero no vuelve a lo alto. Habla bajo tierra. Solamente lo oye aquel que también cava hondo» ${ }^{6}$.

Si para Jean de la Bruyère no hay para el hombre sino tres sucesos: nacer, vivir y morir — «No nos sentimos nacer, sufrimos por morir y anhelamos vivir»—, la biografía de Gómez Dávila podría verse resumida de forma acertada por el filósofo italiano Franco Volpi, en buena medida su descubridor para el mundo académico, mediante tres palabras: nació, escribió, murió. Nació en Bogotá el 18 de mayo de 1913. Escribió básicamente en su casa bogotana tras su vuelta de Francia en 1936, donde pasó su infancia y adolescencia. Murió el 17 de mayo de 1994.

Los elementos básicos de esta biografía los define el propio Volpi: «A los seis años se trasladó con su familia a París, donde asistió a un colegio benedictino recibiendo una educación humanístico-cristiana. Una neumonía, que lo mantuvo en cama casi dos años, lo constriñó a completar en casa su formación con preceptores privados. Consiguió un impecable

\footnotetext{
${ }^{3}$ N. Gómez Dávila, Notas, t. I, nueva edición con prólogo de Franco Volpi, Bogotá, Villegas Editores, 2001, p. 340, nota 340.

${ }^{4}$ Escolios a un texto implícito, p. 80.

5 G. Ch. Lichtenberg, Aforismos, K-I/42, 1, 3. ${ }^{a}$ reimpr., México, FCE, 1995, p. 95. 2010.

${ }^{6}$ K. Kraus, Dichos y entredichos, trad. cast y notas de Alan Kovacsics, Minúscula,
} 
dominio del griego y del latín, y asimismo una envidiable familiaridad con los clásicos del pensamiento y de la literatura mundial. Regresó a Bogota y allí se casó y tuvo tres hijos, y probablemente el rasgo más destacado de su gera diaria. En el curso de los años recogió en su casa —un impotente edificio en estilo Tudor - una majestuosa biblioteca con más de treinta mil volúmenes, donde se recluía cotidianamente, hasta la madrugada, para dedicarse a la lectura y a la escritura, es decir: a la "biblioterapia" como forma de vida» ${ }^{7}$.

Esta biblioterapia se inscribe en una tradición occidental considerada como un «diálogo continuo que atraviesa los veintiocho siglos transcurridos desde los hexámetros de Homero a los últimos versos de Yeats» ${ }^{8}$.

Como sigue diciendo Pizano, en amplias partes del mundo hasta finales del siglo XIX para todas las elites y el primer tercio del siglo XX para algunos menos, esta tradición estaba viva, es decir, se traducía en pensamientos, acciones, lugares comunes. Basta ver cómo para nuestros abuelos las referencias clásicas no se explicaban, apenas se enunciaban; hoy en día, por el contrario, se precisa un largo rosario de referencias bibliográficas. Esta tradición común estaba especialmente viva entre lo que me atrevería a denominar la aristocracia criolla, aún más que entre sus contemporáneos españoles.

Por el contrario, para la generación que empezaba a acudir al colegio en los años treinta, en la que se integra Pizano, esas referencias apenas se mantenían, nulo griego, poco latín y, eso sí, leves referencias que permitían aún añorar la tradición. Luego nada. Los hijos de éstos perdimos la posibilidad de comunicarnos a través de los siglos con la tradición común no sólo en las lenguas originales, sino incluso en las referencias de las buenas traducciones. Hay una enorme fractura expresada en el lema del siglo xx: más gimnasia y menos latín (por cierto, de cierta resonancia nazi).

Ésta es la excepción de Gómez Dávila. Su perfecto conocimiento de todas las lenguas cultas de la tradición y su propia dedicación al estudio le permitieron ser guía de sus amigos y facilitan que su obra realice esa misma función. Del homenaje que en 1988 le rindieron sus amigos me permito

${ }^{7}$ F. VolPI, El solitario de Dios, publicado como introducción a la edición de Atalanta de Escolios a un texto implícito, Barcelona 2009, p. 10. Se trata indudablemente del mejor trabajo publicado sobre la obra del escritor colombiano.

8 Francisco Pizano de Brigard, Semblanza de un colombiano Universal: Las claves de Nicolás Gómez Dávila» en Revista del Colegio Mayor de Nuestra Señora del Rosario, Bogotá, Número 542, vol LXXXI, abril Junio-1988, p. 9-20 cit p. 11. 
recoger esta larga cita donde se describe lo que sintieron ante él y también cómo lo consideraron éstos:

«Para quienes lo han circundado, Nicolás Gómez Dávila ha sido la puerta y el generoso guía en el camino que recorre ese universo; para sus lectores será tal vez la última oportunidad de conocer entre nosotros cómo es un hombre eminentemente civilizado, un espíritu profundamente hecho y nutrido por la plenitud de la riqueza espiritual contenida en el universo occidental. Su obra nos introduce en un mundo ante cuya amplitud de temas y profundidad histórica nuestra visión resulta plana, recortada y curiosamente provinciana. Sus escolios constituyen un comentario continuo a esa rica y compleja vida que se desenvuelve a lo largo de la historia de Occidente. Por su lente van pasando una y otra vez los interrogantes, las reflexiones, los elementos de esa discusión que durante veintiocho siglos ha suscitado la condición humana al hombre occidental»?

\section{IMPOTENCIA ANTE EL MUNDO}

Nuestro autor suministra muchas pistas, algunas equívocas ciertamente, de su actitud. Vimos hasta qué punto su definición como escoliasta, comentador al margen, resulta intencionada. También podemos ver que su distancia y su actitud literaria no muestran sino una forma de impotencia ante un mundo inasumible que, sin embargo, no puede ser destruido: «La ironía transforma en benevolencia el odio impotente» ${ }^{10}$.

De nuevo Volpi define las características de su reaccionarismo:

«Estamos ante un antimodernista radical que se profesa reaccionario no en el sentido político usual, sino en un sentido más bien de principio: reaccionario es aquel que está en contra de todo, porque nada merece conservarse por más tiempo» ${ }^{11}$.

La carencia de originalidad es buscada constantemente por Gómez Dávila. Tiene una raíz ideológica, situarse en una tradición tiene además algo de buscar la compañía de autores del pasado frente a su soledad actual, y así nos dice:

9 Francisco Pizano de Brigard, Semblanza de un colombiano Universal: Las claves de Nicolás Gómez Dávila» Revista del Colegio Mayor de Nuestra Señora del Rosario, N 542, vol 81, abril Junio-1988, p. 11.

10 Escolios a un texto implícito, p. 108.

11 Franco Volpi, Enciclopedia de obras de Filosofia, Herder, Barcelona, 2005, p. 837. 
«Desde mediados del siglo pasado, desde Baudelaire, Flaubert, Kierkegaard, Dostoievski, Ruskin, Burckhardt, es cosa sabida que la fe en el progreso caracteriza al imbécil» ${ }^{12}$.

De hecho, ni su obra ni su persona pueden vincularse estrictamente con el conservadurismo colombiano ${ }^{13}$. Hay quien defiende que Gómez Dávila no puede considerarse estrictamente un reaccionario, en cuanto le falta la afinidad con el hispanismo que sería definitoria de todo reaccionario de Colombia. La tesis es interesante y reveladora, pero no se puede olvidar la francofilia de buena parte de los reaccionarios, actitud que en algunos llega al extremo. El mismo Donoso Cortés, cabeza pensante del reaccionarismo español, dice esto en una carta a un francés sobre el carácter español:

«Acá en España hay que vivir una vida que deja pocos instantes libres para el trabajo intelectual. Las visitas, el paseo, la tertulia, son cosas a las que no se puede faltar impunemente. La holgazanería es el rasgo saliente del carácter español [...] Para el trabajo del pensamiento, ni para ningún otro trabajo, no parece sino que no hemos venido al mundo los españoles» ${ }^{14}$.

Curiosa contradicción con Cioran, externo al pensamiento reaccionario precisamente por su primer filofascismo, que manifiesta algo que no puede sino alagar nuestro decaído orgullo nacional: «Alternativamente, he adorado y execrado numerosos pueblos; nunca se me ha ocurrido renegar del español que hubiera querido ser» ${ }^{15}$.

12 Escolios a un texto implícito, p. 1134.

13 Ciertamente con cuidado debe hacerse esta apreciación, en cuanto si mantuvo amistad con destacados conservadores, pero creo que acierta Abad cuando piensa que este afrancesado no se inserta plenamente en la tradición conservadora colombiana. «Gran parte de los intelectuales colombianos que fueron influenciados por las doctrinas conservadoras y reaccionarias estuvieron conectados con la práctica política, y además de ello, fue notable su admiración por España. Ninguna de estas dos facetas se visualiza en nuestro autor; la primera de ellas es reconocible por la austeridad que le era característica y el alejamiento de la vida social y política de su tiempo. Se sabe que a su casa asistían algunos de los hombres más influyentes en materia política, p.e. Alberto Lleras, Laureano Gómez, entre otros; sin embargo, esto no influyó para que nuestro autor se sintiese atraído hacia la práctica política a la que tantos intelectuales colombianos habían adherido.» P. 50.

${ }_{14}$ Carta de 22 de marzo de 1850 a su editor Veuillot, cita por Federico Suárez, Vida y obra de Donoso Cortés, Ediciones Eunate, Estella, 1997, p. 855.

15 Cioran, Syllogismes de l'amertume cit en Savater, F Esnsayo sobre Cioran, Taurus, Madrid, 1974, p. 40 


\section{ANTIPATÍA ANTE EL CONSERVADURISMO}

Máxime cuando sabemos la escasa simpatía que el reaccionario auténtico muestra por los conservadores en sentido político y con los restauracionistas. Respecto a estos últimos muestra un profundo desdén, que casi me aventuraría a considerar fundamentado, de forma paradójica, en Chateaubriand: «Toda restauración es un jacobinismo invertido» ${ }^{16}$.

Como señala Fumaroli, pese a la inclinación de Chateaubriand por la política restauracionista su experiencia es crítica:

«Por su parte, la ironía y la melancolía de las Memorias de Ultratumba, la angustia profética que hace estremecer de punta a cabo su rememoración, nacen del sentimiento de Chateaubriand de que este precioso patrimonio de costumbres civiles y de "moral de los deberes" acumulado por la "Vieja Europa" aristocrática se erosiona rápidamente bajo el efecto corrosivo de la "moral de los intereses" que vuelve bárbara y brutal la era de las democracias» ${ }^{17}$.

El propio Chateaubriand no se engaña sobre los protagonistas de la Restauración:

«imperialistas y liberales, fue a vuestras manos a las que fue a parar el poder, vosotros que os arrollidasteis ante los hijos de Enrique IV! Era natural que los realistas se sintieran felices de recuperar a sus príncipes y de ver terminarse el reinado de aquel a quien consideraban un usurpador; pero no lo era que vosotros, criaturas de este usurpador, sobrepasarais en exageración los sentimientos de los realistas. Los ministros, los grandes dignatarios prestaron a porfía juramento a la legitimidad; todas las autoridades civiles y judiciales hacían cola para jurar odio a la nueva dinastía proscrita, amor a la antigua estirpe que ellas habían condenado cientos de veces. ¿Quién escribía esas proclamas, esas cartas acusatorias y ultrajantes para con Napoleón de que estaba inundada Francia? ¿Unos realistas? No: los ministros, los generales, las autoridades, elegidos y mantenidos por Bonaparte» ${ }^{18}$.

Todo esto producía una situación extraña, podíamos decir que irreversible. Mucho de la actitud de Gómez Dávila puede rastrearse en las siguientes palabras de Chateaubriand:

16 Escolios p. 714.

17 Chateaubriand, Memorias de Ultratumba, El Acantilado, Barcelona, 2004, p. XLIV.

18 Memorias de Ultratumba, Libro Vigésimo Segundo, Capítulo 23, El Acantilado, p. 1175. 
«Los partidos actuaban sin pensar en la forma de gobierno que habían adoptado; todo el mundo hablaba de Constitución, de libertad, de igualdad, de derechos de los pueblos, y nadie los quería; verborrea de moda; se pedían, de forma irreflexiva, noticias de la Carta, mientras se esperaba que no tardara en fracasar. Liberales y realistas se inclinaban por el absolutismo, atenuado por las costumbres: era el temperamento y la forma de ser de Francia. Dominaban los intereses materiales; no se quería renunciar en modo alguno a lo que se había hecho, se decía durante la Revolución» ${ }^{19}$.

Realmente el reaccionario auténtico sólo en escasas ocasiones torna en conservador: «El reaccionario no se vuelve conservador sino en las épocas que guardan algo digno de ser conservado» ${ }^{20}$.

Es cierto que Cioran, muy leído por Gómez Dávila, definía al reaccionario como el conservador que se ha quitado la máscara. Pero cabe trazar diferencias precisamente en el firme pesimismo del primero y su falta de compromiso con toda situación establecida. De nuevo en el Ensayo sobre el pensamiento reaccionario:

«La doctrina de la Caída ejerce una fuerte seducción sobre los reaccionarios, de cualquier color que sean; los más empedernidos y lúcidos saben además qué recursos ofrece contra el prestigio del optimismo revolucionario: ¿no postula acaso la invariabilidad de la naturaleza humana, condenada sin remedio a la decadencia y a la corrupción? En consecuencia, ningún desenlace, ninguna solución existe en los conflictos que asolan a las sociedades, ni posibilidad alguna tampoco de cambio radical que pudiera modificar su estructura: la historia, tiempo idéntico, es el marco en el que se desarrolla el proceso monótono de nuestra degradación. El reaccionario, ese conservador que se ha quitado la máscara, adoptará siempre lo peor y lo más profundo de las sabidurías: la concepción de lo irreparable, la visión estática del mundo» ${ }^{21}$.

Esta visión sobre el pecado original, que en Cioran parece explicativa, es, sin embargo, afirmada con claridad y contundencia por Gómez Dávila en uno de sus escolios más provocadores: «Los hombres se dividen en dos bandos: los que creen en el pecado original y los bobos» ${ }^{22}$.

19 Memorias de Ultratumba, Libro Vigésimo Tercero, capítulo 20, 1273.

20 Escolios a un texto implícito, p. 496.

${ }^{21}$ E. M. Cioran, Ensayo sobre el pensamiento reaccionario, Montesinos Editor., 1985, p. 28.

22 Escolios a un texto implícito, p. 173. 
De donde procede una posición de Gómez Dávila fundamental cuando estudiemos su concepción sobre el derecho: «Llamar sociales los problemas que dependen de la naturaleza misma del hombre sólo sirve para fingir que podemos resolverlos» ${ }^{23}$.

En este punto, por supuesto, también podemos recordar al mismo Cioran: «Quien habla en nombre de los otros es siempre un impostor» ${ }^{24}$.

Y esto no sólo se aplica a la pura acción política, sino que permite dilucidar la posición ética de cualquiera: «Quienes disculpan su abyección pretendiéndose víctimas de las circunstancias son socialistas doctrinarios. El socialismo es la filosofía de la culpabilidad ajena» ${ }^{25}$.

Por supuesto este tipo de error es interesado. Se afirma que los problemas son solucionables por el Estado para darle a éste un poder que no cederíamos gustosos de otra forma. El extremo se ha alcanzado en la política constructivista de gobiernos como los que hemos disfrutado en nuestros países, que han disminuido la libertad incidiendo en las supuestas libertades: «El político necesita convencer al pueblo de que todos los problemas son sociales para poder esclavizarlo» ${ }^{26}$.

\section{CRÍTICA DEL EXTREMISMO POLÍTICO}

Por otra parte, lo que puede sorprender a algunos es que desde su radical discrepancia ${ }^{27}$ hacia el mundo moderno, Nicolás Gómez Dávila mostrase muy poco afecto por el extremismo político: «El extremismo político sirve para disculpar la mediocridad intelectual» ${ }^{28}$.

O lo que es lo mismo: «Las ideas tiranizan al que tiene pocas».

$\mathrm{O}$ si se prefiere de una forma muy gráfica y climática: «El hombre es un animal de clima medio: en cualquier extremo de una idea muere congelado».

Es decir, hay en Gómez Dávila, como lector amplísimo de lectura sabia y lentamente digerida, como espíritu aristocrático, una enorme liberalidad de trato, una comprensión desde el pesimismo. Un pesimista suavemente escéptico no sólo no puede ser nunca un fanático, sino que además repele

\footnotetext{
23 Escolios a un texto implícito, p. 118.

24 Cioran, Precis de descomposition.

25 Escolios aun texto implícito, p. 77.

26 Escolios a un texto implícito, p. 118.

27 Escolios a un texto implícito, p. 343.

28 Escolios a un texto implícito, p. 338.
} 
al fanatismo. Algunas de sus actitudes pueden, entonces, acercarse a cierto dandismo. Un peculiar dandismo con convicciones, pero que teme con fuerza al predicador y al entusiasta: «Sería interesante averiguar si ha habido prédica que no termine en asesinato» ${ }^{29}$.

Es justo, pues, preguntarse si la característica exclusiva que Abad cree encontrar en Gómez Dávila es propia de este peculiar reaccionario o es común a todo un reaccionarismo literario que se encuentra en incapacidad de actuar en un mundo que le ha sobrepasado. Estos rasgos que Abad cree exclusivos se definirían como: «Alejándose de la construcción teórica de una posición política que dé cuenta de una disposición cuyo fin sea el de cambiar la orientación de la modernidad, el reaccionario, Gómez Dávila en este caso, no se dispone a construir una teoría política, sino a dar testimonio de la purulencia que define el mundo contemporáneo» ${ }^{30}$.

\section{LA SOLEDAD DEL REACCIONARIO AUTÉNTICO}

De aquí procede la soledad de Gómez Dávila en lo que se refiere a su posición teórica, aunque como vimos gozó de un cierto número de amigos que distan de constituir lo que luego se llamó una generación. Su soledad es diversa de la que se predica respecto a otros representantes de la literatura fragmentaria como el propio Lichtenberg, del que se ha dicho: «En sus textos Lichtenberg se presenta como un campeón del aislamiento. Sin embargo, su soledad no debe ser vista como una forma de vida, sino como un principio intelectual (la posibilidad de pensar en sí mismo sin atender a los “ruidos" en derredor)» $\gg^{31}$.

Así probablemente el aislamiento de Gómez Dávila se pareció más al de un Schopenhauer, aunque Gómez Dávila se conformó con su fortuna y no se vio sometido al fracaso de una vida académica como Schopenhauer ${ }^{32}$.

29 Escolios a un texto implícito, p. 182.

30 Alfredo Andrés Abad Torres, Pensar lo implícito, En torno a Gómez Dávila, Pereira, 2008: « p. 43.

31 Juan Villoro, en Georg Christoph Lichtenberg, Aforismos, op cit, P. 21.

32 Este fracaso en la Universidad de Berlín, frente a su aborrecido Hegel, es descrito de la siguiente manera por Safranski: «Todo esto es lo que quería explicar Schopenhauer a un puñado de estudiantes en la Universidad de Berlín durante el verano de 1820. Hegel explicaba en la sala contigua ante un auditorio repleto. En el semestre siguiente, Schopenhauer tendrá que recoger sus bártulos: no se imparte el curso por falta de interés. Eso significa para él una catástrofe existencial. ¿le ayudará su filosofía a superarla? Schopenhauer había hecho una filosofía: ¿Qué hará ahora esta filosofía por el filósofo?» Rüdiger Safranski, Schopenbauer y los años salvajes de la filosofía, Tusquets, Barcelona, 1 ed, 2008. p. 329. 
Su simpatía romántica le precipita en antipatía hacia todo intento de construcción sistemática. Menos confía en la acción de convicción que no proceda de un claro camino personal. Por eso dirá en su libro Textos que: «Para el pensamiento reaccionario, la verdad no es objeto que una mano entregue a otra mano, sino conclusión de un proceso que ninguna impaciencia precipita» ${ }^{33}$.

Por todo ello, sin caer en el error de negar o disminuir la base reaccionaria de su formación o de su biblioteca, son justas las apreciaciones de autores como Abad que insisten en la peculiaridad de Gómez Dávila o, si se quiere, la posibilidad de utilizar su obra desde diversos campos. De nuevo con Volpi:

«Es cierto que entre los volúmenes de su biblioteca se encuentran, en primera fila, los escritos de Justus Möser, el padre del conservatismo rural, y la edición rusa de las obras completas de Kostantin Leont'ev, célebre fustigador del europeo medio como instrumento e ideal de la destrucción universal. Además de Joseph de Maistre, Donoso Cortés y otras fuentes del pensamiento reaccionario que lo han acompañado desde su juventud parisina, tales como Maurice Barres y Charles Maurras, de quienes se podría averiguar la influencia en su formación» ${ }^{34}$.

En otro de sus escasos textos El reaccionario auténtico Gómez Dávila perfila una figura que también es determinable a través del desorden en que se publicaron sus escolios. En ellos se descubre la falta de afán pedagógico, de apologética que define al reaccionario auténtico. Su característica es la conciencia de la aparente esterilidad de sus acciones:

«Si el reaccionario admite la actual esterilidad de sus principios y la inutilidad de sus censuras no es porque le baste el espectáculo de las confusiones humanas. El reaccionario no se abstiene de actuar porque el riesgo lo espante, sino porque estima que actualmente las fuerzas sociales se vierten raudas hacia una meta que desdeña» ${ }^{35}$.

Por ello la figura que construye resulta totalmente ajena al mundo contemporáneo que no puede entender una figura, si se me permite la expresión, tan poco práctica. La extrañeza del progresista la define con precisión: «El progresista radical, por una parte, no comprende cómo el

\footnotetext{
33 Nicolás Gómez Dávila, Textos,ed española, Atalanta Barcelona 2010p. 55.

34 El solitario de Dios, P. 31

35 El reaccionario auténtico, p. 157.
} 
reaccionario condena un hecho que admite, y el progresista liberal, por otra, no entiende cómo admite un hecho que condena» ${ }^{36}$.

Curiosamente existe un paralelismo entre este reaccionario y el tipo sorprendentemente nuevo que Savater creyó identificar en su tesis sobre Cioran, aquel que pese a su intención no deja de mostrarse como un cómplice de un discurso que aborrece:

«Es difícil no colaborar con el Orden casi constantemente, sólo escapan quizá a ello ciertas creaciones ambiguas del arte, del pensamiento, de la política; Cioran edifica su texto en la vigilancia de cualquier complacencia apologética. Será cómplice, como todos los vivientes, pero cómplice involuntario» ${ }^{37}$.

Pero de nuevo con Cioran podemos ver que estos rasgos del colombiano son observables en un gran número de sabios reaccionarios, comenzando por el primero, De Maistre:

«Con frecuencia, el reaccionario no es más que un sabio hábil, un sabio interesado que, explotando políticamente las grandes verdades metafísicas, escruta sin indulgencia ni piedad lo más recóndito del fenómeno humano para proclamar su horror» ${ }^{38}$.

Al quitar valor moral a la Historia no necesita justificarse en la victoria, ni desde su pesimismo buscar esperanzas que no sean estrictamente escatológicas:

«Ser reaccionario es defender causas que no ruedan sobre el tablero de la Historia, causas que no importa perder» ${ }^{39}$.

Evidentemente esta utilización de la Historia se vincula más al escepticismo que deriva de su admirado Tucídides que a los optimistas lanzados a encontrar «el sentido de la Historia» o el trayecto inexorable que lleva no se sabe dónde. Como dice en otro escolio: «El historiador que trata las épocas como simples etapas de procesos convierte la que estudia en mero prólogo de su tiempo, o en prehistoria de su anhelo» ${ }^{40}$.

36 El reaccionario auténtico, p. 152.

37 Savater, Ensayo sobre Cioran, p. 34.

38 E M Cioran Ensayo sobre el pensamiento reaccionario, p. 29.

39 El reaccionario auténtico, p. 157.

40 Escolios a un texto implícito p. 233. 
En este punto se encuentra con lo más granado del pensamiento contemporáneo que, a su juicio, tiene su cumbre en escritores y pensadores que pueden calificarse de reaccionarios según sus propios parámetros, pero que generalmente no recibirían la calificación de tales en la mayor parte de nuestro pensamiento.

La diferencia, por tanto, entre progresista y reaccionario es el triunfo de uno y la razón del otro. El reaccionario, parafraseando a Gómez Dávila, no ocupará nunca el centro de la obra, se limita a predecir el final:

«El progresista siempre triunfa y el reaccionario siempre tiene razón.

Tener razón en política no consiste en ocupar el escenario, sino en anunciar desde el primer acto los cadáveres del quinto» ${ }^{41}$.

Es así como recluta las mentes que le acompañan en su peculiar reaccionarismo. Mentes que describe en el inicio de El reaccionario auténtico:

«Para aplacar sus recelos, el progresista acostumbra interpretar esa actitud intempestiva y chocante como disfraz de intereses o como síntoma de estulticia; pero sólo el periodista, el político y el tonto no se azoran, secretamente, ante la tenacidad con las que las más altas inteligencias de Occidente, desde hace ciento cincuenta años, acumulan objeciones contra el mundo moderno. Un desdén complaciente no parece, en efecto, la contestación adecuada a una actitud donde puede hermanarse un Goethe o un Dostoievski» ${ }^{42}$.

Y de nuevo acierta el bogotano en lo que se refiere a Dostoievski, toda vez que el gran autor ruso, el más grande novelista de todos los tiempos, mantiene una posición literaria reaccionaria ${ }^{43}$ que, sin embargo, no concuerda, en la estricta y concreta política eslavista o en el reaccionarismo utilitario, sin vinculación religiosa, que dirigió en buena medida la acción de los gobiernos zaristas con los que convivió en su madurez.

41 Escolios a un texto implícito, p. 153.

42 El reaccionario auténtico, p. 151.

43 «En todas sus novelas extensas, las convicciones positivas de Dostoievski aparecen principalmente como contraste y trasfondo de las nocivas doctrinas que él deseaba socavar y destruir, o presentar condenadas a autodestruirse. Por ejemplo, en los hermanos Karamazov, aunque su ideal religioso aparece extensamente retratado en el padre Zosimo, este ideal no surge tan directamente de las raíces vivas de sus propias experiencias personales. Sólo en El idiota incluye Dostoievski una descripción de lo que sintió ante el pelotón de fusilamiento, ante su propio encuentro con la inminencia de la muerte.» Joseph Frank Dostoievski, 18651871, FCE, Mexico 1997, P. 357. 
Le aleja, sin embargo, la estricta aproximación al alma rusa que practica el autor de Los hermanos Karamazov (1879-1880) ${ }^{44}$. Don Colacho parece encontrarse más cercano al alma del campesino vendeano que a la del colombiano.

Se trata, por tanto, de la antítesis aristocratizante del sentido popular tradicional que describe el gran autor ruso. Cabe recordar que al resumir El diario de un escritor - patriótico discurso que para más de un intérprete constituyó una conclusión triunfal a su carrera, pronunciado con ocasión del acto de inauguración del monumento moscovita a Aleksandr Sergeievich Pushkin - atribuyó a quien liberó a la moderna literatura rusa de la excesiva artificiosidad caracterizadora de su lengua literaria a lo largo del siglo XVIII y los inicios del siglo XIX de las siguientes características:

«Que Pushkin es el primero que, con su profundamente perspicaz y genial inteligencia y su corazón puramente ruso, encontró y señaló la más importante y enfermiza aparición de nuestra intelectual sociedad históricamente apartada de la tierra y que se eleva sobre el pueblo. Señaló y destacó ante nosotros nuestro tipo negativo, al hombre que se inquieta y no se reconcilia, y que no cree en la tierra natal ni en sus fuerzas originarias, que niega a Rusia y así mismo al final (es decir, su sociedad, la capa intelectual que surgió sobre nuestra tierra natal), que no desea tener nada que ver con otros y que sufre sinceramente» ${ }^{45}$.

En ello se encuentran buena parte de las claves de lectura de Gómez Dávila que, alejado del activismo, no pretende en forma alguna ninguna restauración de un orden ideal recientemente perdido. De ahí la culminación de su definición del reaccionario auténtico que convierte al bogotano en un autor poco utilizable desde la estricta arena política: «El reaccio-

44 Como indica Frank, refiriéndose al esfuerzo de Dostoievski en su primera revista tras su vuelta «La revista de Dostoievski presentaba una ideología conocida entonces como pochvennichvestvo, un retorno a la tierra pochva, un regreso las propias raíces. Su propósito principal era estimular un esfuerzo por colmar la inmensa brecha de la cual había él sufrido tanto, en Siberia, entre los campesinos y la occidentalizada clase superior. Sus cuatro años de vida en un nivel de igualdad con los presos campesinos, creía Dostoievski, le habían dado una visión única de la mentalidad del campesino ruso y le habían mostrado lo quiméricas que eran las expectativas revolucionarias de la intelectualidad radical». Joseph Frank, Dostoievski, los años milagrosos, 1865-1871.FCE, Mexico, 1997. P. 22 vid José Luis López Aranguren, El cristianismo de Dostoievski; Editorial Taurus, Madrid, 1971; Augusto Vidal, «Dostoievski», Siex Barral, Barcelona, 1992.

45 Diario de un escritor, 1880, agosto (número único). Cito la edición de Paul Viejo en Páginas de Espuma, Madrid, 2010, P. 1446. 
nario no es el soñador nostálgico de pasados abolidos, sino el cazador de sombras sagradas sobre doctrinas eternas» ${ }^{46}$.

$\mathrm{Y}$ esto le aproxima a los libros y le aleja del entusiasmo vital de todos los extremismos del siglo xx: «Seamos livresques, es decir: sepamos preferir a nuestra limitada experiencia individual la experiencia acumulada en una tradición milenaria» ${ }^{47}$.

\section{ACTITUD CONTEMPLATIVA}

Alguien podría preguntarse que si Gómez Dávila no pretendía organizar un partido, ni reclamaba una restauración, cuál era la función que se atribuía a sí mismo. Un acercamiento correcto debe partir de la base del conocimiento no utilitario. La verdad es un bien en sí mismo y a su cultivo dedicó el maestro sus mejores horas. Quiere decirse que Gómez Dávila leía y comentaba por el puro placer de leer y comentar, de ahí su resistencia a la publicación que sólo rompieron las «indiscreciones» de algunos familiares.

Sabida es la sentencia de Gómez Dávila sobre los filósofos idealistas: «O se pertenece a la posteridad de Hegel o se pertenece a la posteridad de Schopenhauer, tertium non datur» ${ }^{48}$. A este respecto hay quien sostiene que esta recuperación de la contemplación es debida básicamente a la postura de Arthur Schopenhauer frente a G. W. F. Hegel y los idealismos e historicismos que le siguieron. De nuevo nos vemos obligados a citar a Safranski:

«En Schopenhauer la felicidad de la visión está ligada, pues, al abandono de todo esfuerzo para controlar la vida práctica, la historia y las maquinaciones de la sensualidad. Se trata de la misma actividad que, en tiempos anteriores, había recibido otro nombre: vita contemplativa.

Estilo de vida con una tradición respetable: el recogimiento como apertura hacia la verdad.

Y aunque la verdad desinteresada había gozado antaño de elevado prestigio, a principios del siglo XIX su ascendiente había decrecido de forma considerable. No podía ser de otra manera en una época para la que la política se convirtió en destino y que empezaba a creer que la historia, y con ella también la felicidad, podía ser "hecha". También el espíritu de la acción penetró en la metafísica» ${ }^{49}$.

\footnotetext{
46 El reaccionario auténtico, p. 159

47 Escolios a un Texto implícito, p. 370.

48 «Escolios a un texto implícito», p. 602.

49 Rüdiger Safranski, Schopenhauer y los años salvajes de la filosofía, op cit, p. 293.
} 
La paradoja del político dice mucho de la base del tipo del reaccionario que Gómez Dávila pretendía ser:

«El problema político es radicalmente insoluble, porque consiste en la exigencia contradictoria de imponer por la fuerza valores que se anulan cuando la fuerza los impone.

El político traiciona igualmente, sea que admita la impotencia del bien, sea que lo pertreche de armas» ${ }^{50}$.

En esta labor callada la posición del reaccionario sirve a un fin claro que no es el triunfo político, sino sencillamente la compresión. Con mucha más gracia se expresa el autor: «El pensamiento reaccionario no asegura éxito alguno a sus adeptos, meramente les garantiza que no dirán tonterías» ${ }^{51}$.

Y refuerza su escepticismo con la probable explicación de su resistencia a publicar y su nulo afán proselitista: «El primer paso de la sabiduría está en admitir, con buen humor, que nuestras ideas no tienen por qué interesar a nadie» ${ }^{52}$.

Falsa modestia de nuevo que procede de una profunda ironía sobre el progreso del hombre: «La humanidad no acumula soluciones, sino problemas» ${ }^{53}$.

Este escepticismo —que en la arena política debe mucho al historiador Tucídides y en la actitud fundamental entronca sin dificultades con el Montaigne de la Apología de Raimundo Sabunde (1575-1576)_ permite sus frases más agudas, provocadoras y brillantes, que son la causa, en mi opinión, de la seducción de Gómez Dávila a una multitud de lectores de muy distinto pelaje. Véase si no su más certera ironía sobre el desastre de las buenas intenciones: «La izquierda desembarcó en América con el padre Las Casas. Y aconteció, paradigmáticamente, lo que suele acontecerle a la izquierda: aquí no libertó al indio, pero esclavizó al negro» ${ }^{54}$.

Así define su beatus ille, aunque frente al poeta, él nunca tuvo la necesidad de añorar, pues era la forma de vida que practicaba. Su definición de vida beata coincide precisamente con la forma de vida que alcanzó: «Vivir con lucidez una vida sencilla, callada, discreta, entre libros inteligentes, amando a unos pocos seres» ${ }^{55}$.

50 Escolios a un texto implícito, p. 382.

51 Escolios a un texto implícito, p. 296.

52 Ibid., p. 237.

53 Ibid., P. 176.

54 Ibid., p. 407.

55 Ibid., p. 407. 
Aunque persiste siempre en él la conciencia de la inadecuación de la vida humana, la escasa esperanza que cabe esperar en nuestro destierro: «Cuando la providencia nos concede el destino que anhelábamos, pronto descubrimos que aceptarlo requiere una resignación desolada» ${ }^{56}$.

Aun así Colacho cede a la tentación de buscar una finalidad a sus aforismos que no es otra sino el desenmascaramiento de la realidad que realiza el pensador solitario; para ello pasa a jugar a la paradoja en uno de sus escolios más reveladores: «Los que denuncian la esterilidad del reaccionario olvidan la noble función que ejerce la clara proclamación de nuestro asco» ${ }^{57}$.

Otras veces la función noble se diluye ante la mera actitud personal. Los escolios construyen un sujeto que, pese a sus debilidades, encuentra su lugar en la pura veracidad: «La resistencia es inútil cuando todo se conjura en el mundo para destruir lo que admiramos. Siempre nos queda, sin embargo, un alma insobornable para contemplar, para juzgar y para desdeñar» ${ }^{58}$.

\section{LA PREOCUPACIÓN ESENCIAL TEOLÓGICA}

En este contexto, absolutamente ajeno a una intención proselitista, se muestra por parte de Gómez Dávila su especial apertura y su profunda preocupación por la teología: «No hablo de Dios para convertir a nadie, sino porque es el único tema del cual vale la pena hablar» ${ }^{59}$.

Y aquí vuelve del revés la genealogía de su admirado Nietzsche para afirmar paradójicamente exactamente lo contrario: «El hombre no crea a sus dioses a su imagen y semejanza, sino se concibe a imagen y semejanza de los dioses en que cree» ${ }^{60}$.

En este punto, y contra el núcleo de los modernos que abandonan la preocupación teológica o la reducen al control del puro racionalismo, Gómez Dávila enlaza con toda una tradición discrepante que piensa que lo religioso es lo único importante. Aunque se acerca de forma diversa a Cioran, a nuestro autor le son aplicables los caracteres que para Savater

\footnotetext{
Ibid., p. 263.

56 Ibid., p. 115.

57 Ibid., p. 119

58 Ibid., p. 267.

59 Ibid., p. 140

60 Ibid., p. 114
} 
definen al rumano: «Cioran dedica numerosas páginas de su obra a divagar sobre el eterno problema de la divinidad, las religiones, las Iglesias, los teólogos y los herejes, el final del paganismo [...] Se siente más cerca del lenguaje de un Tertuliano, de un Agustín o de un Pascal que del de Hegel o Husserl» ${ }^{61}$.

Pero la vinculación de Gómez Dávila respecto a Cioran se hace igualmente patente en sus aborrecimientos. Algunos de los escolios más duros del bogotano parecen inspirados en este rasgo del que en otro ámbito se ha ocupado Savater: «Lo que fastidia a Cioran es la fase actual de esplendor público y decadencia privada de la Iglesia, su carácter puramente cultural, nada terrible ni polémico; quizá cuando pierda sus últimos prestigios y vuelva a las catacumbas, la fe sea interesante de nuevo [...] para sus adversarios» ${ }^{62}$.

Esto sólo es posible desde la soledad. Una soledad buscada que permite la completa libertad a la que aspiraba Gómez Dávila: «Limitar nuestro auditorio limita nuestras claudicaciones. La soledad es el único árbitro insobornable» ${ }^{63}$.

De hecho, esta soledad le aísla del contexto literario en el que, supuestamente, debería haberse insertado. Como dice Abad: «En el terreno literario, y específicamente en su "oficio" de escritor, los rasgos que lo definen son también excéntricos, por cuanto en su desenvolvimiento como escritor se definen aspectos que lo extraen de una posible inmersión en la comunidad intelectual y literaria a la cual, por motivos generacionales, debería haber pertenecido» ${ }^{64}$.

Solitario que mantiene una distancia desdeñosa hacia lo que con acierto denominaba la clase media de la inteligencia: «La clase media de la inteligencia es quejumbrosa y gemebunda» ${ }^{65}$.

Soledad imprescindible para no convertirse en cómplice; desgracia, añadiríamos nosotros, en la que incurre todo el que se reúne o se integra en un esfuerzo común: «En este siglo toda empresa colectiva edifica prisiones. Sólo el egoísmo nos impide colaborar en vilezas. Hoy los copartícipes terminan en cómplices» ${ }^{66}$.

Se explicaría asimismo en este extrañamiento la falta de recepción de Gómez Dávila en Colombia frente a su enorme éxito en Alemania, o en

${ }_{61}$ Fernando Savater, Ensayo sobre Cioran, op cit, P. 88

62 Fernando Savater, Ensayo sobre Cioran, p. 90.

63 Escolios a un texto implícito, p. 70.

64 Abad p. 24.

${ }_{65}$ Escolios a un texto implícito, p. 328.

66 Escolios a un texto implícito, p. 71. 
Austria, o en Italia. Para algunos esta inadecuación se produciría por la actitud americana hacia la Ilustración y la Revolución, en cierta manera fundantes del Nuevo Mundo frente a la actitud más comprensiva de la Vieja Europa ${ }^{67}$. Como integrante de la cultura española en el Viejo Mundo, pero caracterizada hoy en día por la ramplonería políticamente correcta, me atrevo a apuntar que la diferencia de recepción esta marcada por la diversa altura de la vida cultural italiana o alemana respecto a la española o colombiana, dicho sea con toda la intención de molestar.

Justificación del egoísmo que surge de la revelación de las máscaras de las supuestas generosidades que se dan precisamente en dos de las especies más rechazadas por el escritor solitario: el izquierdista y el clero con conciencia social.

Como dice en una brillante paradoja que rompe simultáneamente el tópico culturalista y el tópico social: «Ni la religión se originó en la urgencia de asegurar la solidaridad social, ni las catedrales fueron construidas para fomentar el turismo» ${ }^{68}$.

El egoísmo concreto y realista se opone así a la abstracción supuestamente generosa, desenmascarada por el bogotano. A quienes se tiene por buenos en nuestro tiempo son condenables y a la inversa: «Quienes defienden lo existente luchan por algo concreto: un privilegio, una estructura social, un bien encarnado; en contra, quien batalla por un programa abstracto puede creer que defiende lo universal. El izquierdista se cree generoso porque sus metas son borrosas» ${ }^{6}{ }^{9}$. O si se prefiere: «Participar en empresas colectivas permite hartar el apetito sintiéndose desinteresado» ${ }^{70}$.

Y finalmente en una sentencia definitiva que choca con una larga época de exaltación de sujetos que centran su actividad política en las buenas intenciones: «Todo individuo con ideales es un asesino potencial» ${ }^{71}$.

De ahí su conciencia de inconformidad y rebeldía frente al paradigma de conformismo: «El perfecto conformista en nuestro tiempo es el ideólogo de izquierda» ${ }^{72}$.

67 Carlos B. Gutierrez, La crítica a la democracia en Nietzsche y Gómez Dávila, Ideas y valores., Revista Colombiana de Filosofía, abril, número 136, Universidad Colombiana, Bógota, Colombia, p. 127.

68 Escolios a un texto implícito, p. 84.

69 Ibid., p. 77.

70 Ibid., p. 130.

71 Ibid., p. 321.

72 Ibid., p. 1382. 


\section{LA LIBERTAD EN GÓMEZ DÁVILA}

La causa aristocratizante y disidente de Gómez Dávila apunta a la libertad, uno de los lemas del autor. Empresa sin esperanza, parece ser al decir de Hannah Arendt, plantear la cuestión de que sea la libertad ${ }^{73}$. En esta causa, como en todo, Gómez Dávila debe hacer la genealogía de la falsa libertad moderna que garantiza la opresión. La libertad entendida como la fuerza inmanente de la historia que, al decir de Antonio Gramsci, destruye todo esquema preconcebido ${ }^{74}$. No debiera sorprendernos que en dicha crítica es donde probablemente sea mayor el aprecio de todo tipo de disidentes.

Sus referencias a la libertad parten evidentemente de su antropología pesimista. De nuevo es su obra Textos I, publicada casi a traición contra su parecer, la que nos da una leve referencia de lo que es la base de su pensamiento. En esta antropología la libertad aparece como una cualidad limitativa, pero, sin embargo, descriptora de un esfuerzo titánico. Es difícil igualar su prosa: «Somos libres de postular los fines más diversos, libres de ejecutar las acciones más contrarias, libres de internarnos en las selvas más oscuras, pero nuestra libertad es sólo una libertad de errar. Si somos dueños de mutilar la promesa inscrita en nuestra carne, su determinación excede nuestro siervo albedrío». Y añade: «La libertad no se alza como una plataforma sideral, para que el hombre se trace desde ella una ruta arbitraria entre los astros. La libertad no es poder de fijar metas, sino el poder de malograrlas». Condenados a la libertad, en una clave existencialista define el riesgo de la libertad: «La libertad es nuestro riesgo, el noble privilegio de incumplir nuestro deber». No parece, sin embargo, que pueda despreciarse esta cualidad que nos diferencia de la animalidad (ingenua) y de la materia (ciega): «El animal avanza, imperturbable, hacia la plenitud de su esencia, y la materia la realizaron su existencia sola. El hombre se estremece y oscila al borde de sí mismo. Nunca es blanco donde vibra la flecha clavada, sino aguda flecha en el viento» ${ }^{75}$.

Es mas adulta esta limitación, y por tanto mas libre, que la pretenciosa afirmación del iluminismo. Cierto que Gómez se agarrará a asideros que

73 Hannah Arendt, What is Freedon?, Between past and Future, 1961, 2 ed 1968, Entre el pasado y el futuro. Ocho ejercicios sobre la reflexión política. Trad. Ana Poljak. Península, 1993, 2003

74 Antonio Gramsci, Antología, Ed de Manuel Sacristán, ed Siglo XXI, 1975.

75 Textos, op cit par 19-20. 
le están negados a quienes se refugiaron en los siglos XIX y XX, precisamente en la negación.

Su posición de partida se parece a la de Ernst Junger y se traduce en una crítica a la evolución de la sociedad en el siglo xx, cierto que el alemán mantiene una valoración harto positiva del siglo XIX que es más matizable en Gómez Dávila, en este extremo mas auténticamente reaccionario. En su texto sobre el dolor afirmaba Junger refiriéndose a la nostalgia del siglo XIX: «La mencionada nostalgia parece justificada si tomamos como criterio la libertad personal y el grado en que se mantiene alejado de la persona singular el dolor. Es efectivamente extraordinario el grado de seguridad que existe en el siglo XIX, lo cual se debe a una coincidencia de circunstancias afortunadas» ${ }^{76}$.

Esta apuesta por la libertad concreta acercaría a Gómez Dávila a la tradición de los aristócratas como Chateaubriand o Tocqueville, que fueron muy conscientes del riesgo para ésta de las pretensiones igualitarias y radicales del jacobinismo. Un espíritu liberal, no en el sentido político del término, que cabe observar también en buena parte del conservatismo posterior.

Por otro lado, sin embargo, la libertad buscada en lo concreto entronca con el pensamiento tradicional, especialmente con el tradicional español, que opone la libertad real y concreta a las llamadas a la libertad inconcreta ${ }^{77}$.

Una forma de libertad que tiene por supuesto referentes en el republicanismo aristocrático romano, del que pueden encontrarse también eco en Gómez Dávila. Esta libertad es precisamente en Gómez Dávila medio de la realización personal en el propio espíritu aristocrático, como parece afirmar en otro de sus escolios: «La libertad no es un fin, sino un medio. Quien la toma por fin no sabe qué hacer cuando la obtiene» ${ }^{78}$.

En esta distancia aristocrática aparece la libertad del hombre sólo, de indudables rasgos nietzscheanos. Pero su visión tradicional inserta a este sujeto insobornable en un orden jerárquico acorde es este caso con el pensamiento tradicional: «Una muchedumbre homogénea no reclama libertad. La sociedad jerarquizada no es meramente la única donde el hombre puede ser libre, sino también la única donde le urge serlo» ${ }^{79}$.

76 Ernst Junger, Sobre el dolor, trad de Andres Sanchez Pascal, Tusquets Barcelona, 1995,P. 27.

77 Francisco Elías de Tejada y Spínola, Libertad abstracta y libertades concretas, Speiro, Madrid, 1968

78 Escolios a un texto implícito. P. 72.

79 Escolios a un texto implícito p. 72. 
Realmente la libertad del hombre se sitúa en la referencia a Dios, de nuevo transformando y aprovechando, es decir, tratando a través del escolio la obra de Kant: «Depender sólo de la voluntad de Dios es nuestra verdadera autonomía» ${ }^{80}$.

Emulación de excelencia que choca con la situación de la democracia, donde debe ocultarse toda inteligencia precisamente por el predominio del tonto. Hay aquí ecos de Gracián, pero curiosamente esos ecos no se paran a pensar en la enorme tontería que puede reinar en una sociedad tan estrictamente jerarquizada como la española del siglo XVII.

Casi nos atreveríamos a decir que Gómez atribuye a veces a nuestro tiempo males generales de toda organización humana. Dígase en su descargo que la actitud contemporánea de proyectar las críticas sobre el pasado es especialmente estúpida.

Pero esta valoración de la libertad coincide con un escepticismo notable sobre la naturaleza humana. En efecto, la posición de Gómez Dávila de crítica hacia la sociedad contemporánea no se fundamenta en una apelación a los grandes hombres del pasado, como haría un Catón, frente a los insignificantes del presente. Gómez Dávila, aunque es cierto que piensa que el hombre contemporáneo es especialmente tonto, probablemente por la primacía actual del más tonto, no desdeña la universalidad del aserto para cubrirse con una época que fuese inteligente. Así, toda política debe prevenirse de la idiotez universal: «Sólo la libertad limita las abusivas intervenciones de la ignorancia. La política es la ciencia de las estructuras sociales adecuadas a la convivencia de seres ignorantes» ${ }^{81}$.

O como diría Gracián: «Son tontos todos los que lo parecen y la mitad de los que no lo parecen. Alzose con el mundo la necedad y si hay algo de sabiduría es estulticia con la del Cielo» ${ }^{82}$. Aunque creo que, en este ámbito, es muy difícil alcanzar a Lichtenberg: «Hay ineptos entusiastas. Gente muy peligrosa» ${ }^{83}$.

Este peligro del entusiasta que se torna especialmente grave en el político es especialmente tratado por Gómez Dávila, de nuevo con especial brillantez formal. Lo interesante es que el entusiasmo y el imbécil se combinan con cualquier principio, en cualquier idea, nada está libre del riesgo de ser adoptado por éstos. Son este tipo de observaciones, como hemos dicho, por irritantes que parezcan, las que explican el éxito de Gómez

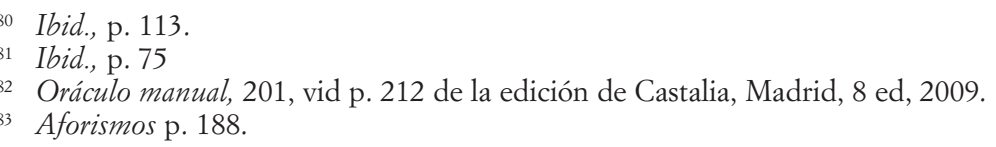


Dávila entre personas diversas: «Nada hay en el mundo que el entusiasmo del imbécil no logre degradar» ${ }^{84}$.

Y cuando dice nada se refiere literalmente a nada, es decir, a todo. No hay palabra, principio o valor, político, moral o religioso que no ese desgastado de forma, quizás, irreversible.

Cuando la jerarquía cede paso a la muchedumbre el resultado no es nunca, a juicio de Gómez Dávila (que vivió la expansión totalitaria y bebió en el antijacobinismo reaccionario), la extensión de la libertad, sino la imposición del terror: «La presencia política de la muchedumbre culmina siempre en un Apocalipsis infernal» ${ }^{85}$.

Actitud muy repetida desde la publicación en 1790 de las Reflexiones sobre la Revolución Francesa de Burke ${ }^{86}$ que constituye la base de toda las críticas de las abstracciones revolucionarias y que había encontrado en Lichtenberg un comentarista eficaz: «En la Francia libre donde ahora uno puede ahorcar a quien quiera» ${ }^{87}$.

Sin ánimo de extendernos en comparaciones —siempre indeseables-, yo creo que la ironía de Nicolás Gómez Dávila alcanza en este ámbito límites superiores: «Las revoluciones democráticas inician las ejecuciones anunciando la pronta abolición de la pena de muerte» ${ }^{88}$.

La opción debería ser entonces la ley que domina la pasión excesiva o que salvaguarda las libertades. Pero nuevamente sorprende Gómez Dávila. Con notable intuición jurídica muestra su escepticismo hacia la abundancia de normas que asfixian finalmente las libertades: «La legislación que protege minuciosamente la libertad estrangula las libertades» ${ }^{89}$.

Más aún se inclina por una moderación que sólo puede surgir del escepticismo en una línea cuyos orígenes se remontarían a Tucídides, Montaigne o el propio Schopenhauer: «Una nación civilizada no debe admitir que la gobiernen sino escépticos» ${ }^{90}$.

El propio Cioran había manifestado una posición similar respecto al peligro de los políticos entusiastas en la sociedad democrática y la necesidad de sobrevivir mediante políticos escépticos. Un hombre político naif es a sus ojos una desgracia para su nación, en ese sentido siempre con Cio-

\footnotetext{
84 Escolios a un texto implícito, p. 220.

85 Escolios a un texto implítico, p. 85.

86 M Buttler, ed «Burke, Paine and the Revolution Controversy, Cambridge, University Press, 1984.

87 Lichtenberg,Aaforismos, p. 203.

88 Escolios a un texto implicito. P. 194.

89 Escolios a un texto implícito p. 85.

90 Escolios a un texto implícito, p. 330.
} 
ran es curioso ver cómo se equivocan personas que se creen muy inteligentes. Los verdaderos hombres políticos serían aquellos que no se hacen ninguna ilusión, los otros serían peligrosos para su nación ${ }^{91}$.

Es en este contexto donde aparece la función de los límites del poder, que en el mundo posrevolucionario parecen creados para frenar los excesos de la revolución. De ahí el afecto de Gómez Dávila hacia ciertos liberales. Ya hemos visto su relación teórica con Chateaubriand. Aún más explícita es la que mantiene con Alexis de Tocqueville: «Nada más noble que el aristócrata liberal — como Tocqueville—, para quien la libertad de todos es el privilegio que compete defender a la clase dirigente» ${ }^{92}$.

91 Entretien avec Branka Bogavac Le Compte, en Cioran Oeuvres, Quarto Gallimard, Paris, 1995, p. 1775.

92 Escolios a un texto implícito, p. 79.Vid Raymond Aron, «La definition liberále de la liberté»,: Alexis de Tocqueville et Karla Marx, en Archives europeennes de sociologie, 1964, 5. 